\title{
Commentary: Nordic cardiothoracic training: Different approaches to common challenges
}

\author{
Alexander P. Nissen, MD, ${ }^{a}$ and Tom C. Nguyen, $\mathrm{MD}^{\mathrm{b}}$
}

\footnotetext{
From the a Department of Surgery, San Antonio Military Medical Center, Fort Sam Houston, San Antonio, Tex and ${ }^{\mathrm{b}}$ Department of Cardiothoracic and Vascular Surgery, University of Texas Health Science Center Houston, McGovern Medical School, Houston, Tex.

Disclosures: Dr Nguyen is a consultant for Edwards Lifesciences, Abbott, and LivaNova. Dr Nissen has nothing to disclose with regard to commercial support.

Received for publication Aug 4, 2019; accepted for publication Aug 5, 2019; available ahead of print Oct 16, 2019.

Address for reprints: Tom C. Nguyen, MD, 6400 Fannin St, Suite 2850, Houston, TX 77030 (E-mail: tom.c. nguyen@gmail.com).

J Thorac Cardiovasc Surg 2020;159:1009-10

$0022-5223 / \$ 36.00$

Copyright (C) 2019 by The American Association for Thoracic Surgery

https://doi.org/10.1016/j.jtcvs.2019.08.049
}

In this issue of the Journal, Mennander and colleagues ${ }^{1}$ provide an insightful summary of cardiothoracic surgical training in the Nordic countries (collectively Sweden, Denmark, Finland, Norway, and Iceland). ${ }^{1}$ Although Iceland does not offer cardiothoracic training, their surgeons are trained in neighboring Nordic nations, and the remaining countries share important similarities. Mennander and colleagues $^{1}$ keenly highlight different approaches to common challenges faced in training the next generation of Nordic cardiothoracic surgeons. In addition to examinations of international training paradigms, a larger global comparison is warranted.

Throughout the Nordic countries, citizens enjoy universal health care through a single-payer system, with all cardiothoracic surgeons practicing at state University hospitals ( 7 in Sweden, 4 in Denmark, 5 in Finland, 4 in Norway, and 1 in Iceland) under a model of shared clinical volume and reimbursement, whereas applicants for cardiothoracic residency apply directly to each institution. Although each nation has slightly different requirements for prerequisite surgical training (9-24 months) before cardiothoracic residency, specific case requirements, and methods for board certification, key challenges faced in training future cardiothoracic surgeons transcend borders.

Adequate operative experience and independence comprise a chief concern in relatively less populous nations, compounded by the limited 40-hour workweek currently in effect across the Nordic countries. Collectively, the use of competency-based training progression, "off-the-job" training through simulation, wet labs, and other courses, along with the emphasis on surgical mentorship, are critical to ensuring competency. Currently, Finland is the only nation requiring both written and oral examination for licensure, whereas the remaining countries rely on oral examination, case logs, and certification by a department chair

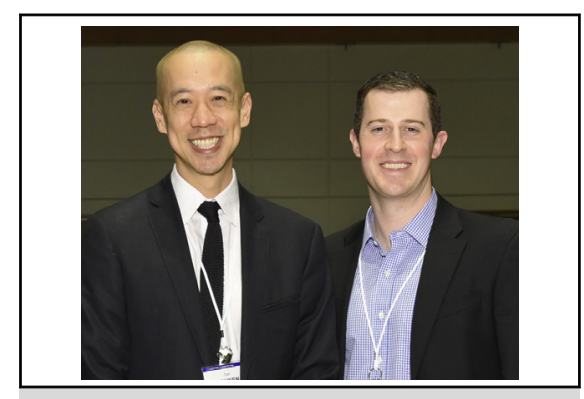

Tom C. Nguyen, MD (left), and Alexander P. Nissen, MD (right)

\section{Central Message}

Several challenges facing the future of cardiothoracic surgery represent unifying factors across the Nordic countries.

See Article page 1002 .

or senior consultant. After certification, further subspecialization (eg, transplantation, congenital) is relatively infrequent, and it is driven as much by the needs of a particular center as by the desire of junior surgeons for additional training. The competency-based model also lends itself to additional time spent performing research, which is quite common, with as many as $25 \%$ of Nordic physicians also obtaining a $\mathrm{PhD}$ during their training.

One drawback of the article is a relative dearth of any discussion related to how Nordic countries plan to address the ongoing transcatheter revolution in cardiothoracic surgery. Nationwide volumes of transcatheter procedures remain relatively low, and creative solutions will likely be necessary to ensure trainee competence. Mennander and colleagues ${ }^{1}$ are also unclear regarding the degree to which junior surgeons continue to function in apprentice-type roles after licensure while working under senior consultant colleagues. Additional granularity regarding the relatively subjective licensure process could also prove enlightening.

Overall, this article provides valuable insights into the training methods used to address a unique set of challenges facing aspiring Nordic cardiothoracic surgeons, and adds to the Journal's growing compendium of publications addressing cardiothoracic, cardiovascular, and cardiac surgical training globally. ${ }^{2-7}$ Several challenges facing the future of cardiothoracic surgery represent unifying factors across the Nordic countries. Perhaps a broader 
comparison of international training paradigms is needed to highlight the strengths and weaknesses of each, while fostering international collaboration, exchange of ideas, and improvement in the training experience for the future vanguard of our specialty.

\section{References}

1. Mennander A, Gubjartsson T, Jeppsson A, Hjortdal V, Tønnessen T. Specialist training for cardiothoracic surgery in the Nordic countries. J Thorac Cardiovasc Surg. 2020;159:1002-8.

2. Noly PE, Rubens FD, Ouzounian M, Quantz M, Shao-Hua W, Pelletier M, et al. Cardiac surgery training in Canada: current state and future perspectives. $J$ Thorac Cardiovasc Surg. 2017;154:998-1005.
3. Rocha RV, Almeida RMS. Cardiac surgery residency in Brazil: how to deal with the challenges of this unique specialty. J Thorac Cardiovasc Surg. 2018;156: 2227-32.

4. Shapira OM, Sahar G, Raanani E. Cardiothoracic surgery training in Israel: a critical look at the past, aiming for a better future. J Thorac Cardiovasc Surg. 2016; 151:1508-15.

5. Shi WY, Oldfield Z, Tam R, Cochrane AD, Smith JA. Cardiothoracic surgery training in Australia and New Zealand. J Thorac Cardiovasc Surg. 2018;156: 718-25.

6. Tchantchaleishvili V, Barrus B, Knight PA, Jones CE, Watson TJ, Hicks GL. Sixyear integrated cardiothoracic surgery residency applicants: characteristics, expectations, and concerns. J Thorac Cardiovasc Surg. 2013;146:753-8.

7. Zakkar M, Benedetto U, Angelini GD, Murphy G, Shah R, Jahangiri M, et al. Cardiothoracic surgery training in the United Kingdom. J Thorac Cardiovasc Surg. 2019;157:1948-55. 